\title{
Synthesis, Characterization, and Photocatalysis of ZnO and Er-Doped ZnO
}

\author{
Kai-sheng Yu, ${ }^{1,2}$ Jian-ying Shi, ${ }^{3}$ Zai-li Zhang, ${ }^{1,2}$ Yong-mei Liang, ${ }^{1,2}$ and Wei Liu ${ }^{1,2}$ \\ ${ }^{1}$ School of Environmental Science and Engineering, Sun Yat-sen University, Guangzhou 510275, China \\ ${ }^{2}$ Guangdong Province Key Laboratory of Environmental Pollution Control and Remediation Technology, \\ Guangzhou 510275, China \\ ${ }^{3}$ School of Chemistry and Chemical Engineering, Sun Yat-sen University, Guangzhou 510275, China
}

Correspondence should be addressed to Wei Liu; esslw@mail.sysu.edu.cn

Received 30 March 2013; Accepted 8 July 2013

Academic Editor: Xuedong Bai

Copyright (C) 2013 Kai-sheng Yu et al. This is an open access article distributed under the Creative Commons Attribution License, which permits unrestricted use, distribution, and reproduction in any medium, provided the original work is properly cited.

$\mathrm{ZnO}$ and Er-doped $\mathrm{ZnO}$ with different molar ratios of $\mathrm{Er} / \mathrm{Zn}$ were prepared using the homogeneous precipitation method. The photocatalysts prepared were characterized using scanning electron microscopy, transmission electron microscopy, X-ray diffraction (XRD), UV-vis spectroscopy, and photoluminescence spectroscopy. The results showed that the Er-doped ZnO displayed characteristic wurtzite-type peaks in the XRD spectra. The Er-doped ZnO absorbed much more light than $\mathrm{ZnO}$ in the ultraviolet region. And the doping of Er into $\mathrm{ZnO}$ enhanced the intensity of the fluorescence emission. The degradation of methylene blue (MB) solution demonstrated that the photocatalytic activity of $\mathrm{ZnO}$ was significantly improved with Er doping.

\section{Introduction}

$\mathrm{ZnO}$ is a semiconductor with a wide band gap $(3.3 \mathrm{eV})$ and a large exciton binding energy and is abundant in nature and environmentally friendly; these characteristics make this material attractive for many applications, including solar cells, optical coatings, photocatalysts, and electrical devices [1]. Researches have shown that $\mathrm{ZnO}$ exhibits better photocatalytic efficiency than $\mathrm{TiO}_{2}$ for the removal of organic compounds in water matrices [2]. ZnO-based photocatalysts have received much attention because of their excellent properties, which include their high chemical stability, their nontoxicity, and their abundance in nature.

Recently, environmental problems such as air and water pollution have provided the impetus for sustained fundamental and applied research in the area of environmental remediation. $\mathrm{ZnO}$ has proven attractive as a photocatalyst material, because it shows high catalytic efficiency and is of low-cost and environmentally sustainable $[3,4]$. $\mathrm{ZnO}$ has emerged as a more efficient catalyst for the detoxification of water, because it generates $\mathrm{H}_{2} \mathrm{O}_{2}$ more efficiently [5], and it has high reaction and mineralization rates. It also has a higher number of active sites with high surface reactivity. $\mathrm{ZnO}$ has been demonstrated as an improved photocatalyst compared with commercialized $\mathrm{TiO}_{2}$, based on its larger initial activity rates, and its efficient absorption of solar radiation. However, $\mathrm{ZnO}$ has almost the same band gap $(3.2 \mathrm{eV})$ as $\mathrm{TiO}_{2}$. The modification of $\mathrm{ZnO}$ via doping with metal ions has been developed as an effective method to promote photocatalytic activity [6-9]. There have been many studies reporting the optical properties of Er-doped $\mathrm{ZnO}$, and some of them specifically, the photocatalysis of Er-doped $\mathrm{ZnO}$ [9-15].

This paper reports a simple route for the preparation of undoped and Er-doped zinc oxide nanoparticles via the chemical precipitation method. The prepared nanoparticles were characterized and then used as a photocatalyst in the photodegradation of methylene blue. Methylene blue is a blue, organic cationic thiazine dye that has been commonly employed as a model dye to evaluate the photocatalytic activity among other photosensitizing dyes like eosin Y, pyrene, and so forth.

\section{Experimental}

2.1. Synthesis. Homogeneous precipitation [10] is one of the most successful and easy to conduct techniques for 


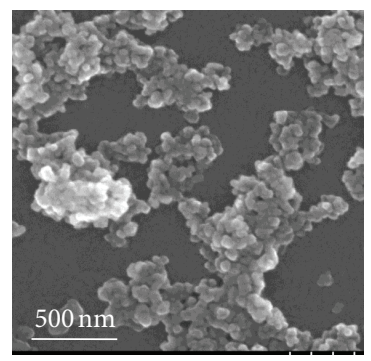

(a)

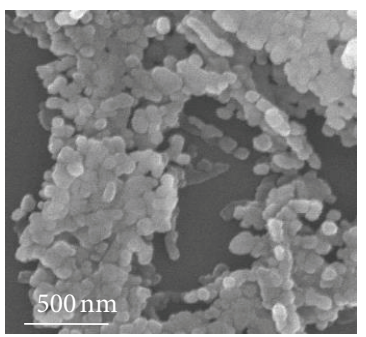

(b)

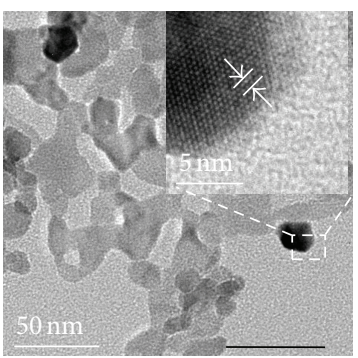

(c)

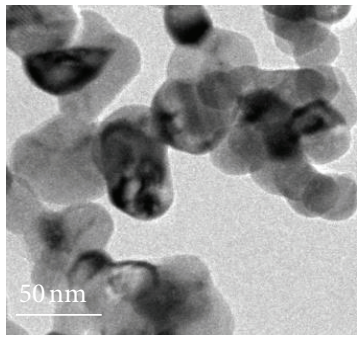

(e)

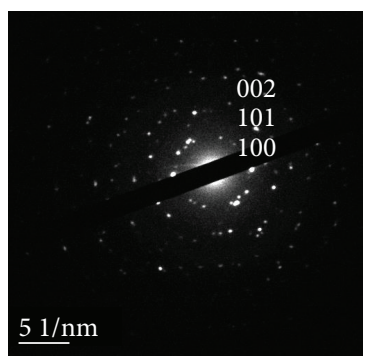

(d)

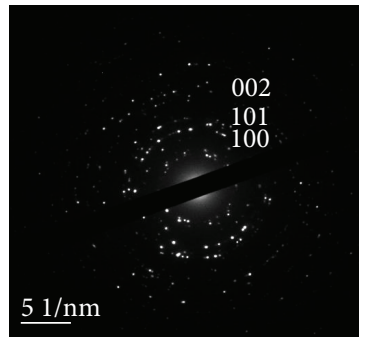

(f)

FIgure 1: (a), (c), (d) SEM/TEM image of ZnO. (b), (e), (f) SEM/TEM image of Er-doped ZnO.

synthesizing Er-dopped $\mathrm{ZnO}$ powders among solid-state reaction method $[9,15]$, the spray deposition technique method [11], sol-gel method [13], and so forth. Briefly, with urea as a precipitating agent, erbium nitrate (AR, 99.99\%) and zinc acetate were added to a water bath at $80^{\circ} \mathrm{C}$ and heated for $4 \mathrm{~h}$. This mixture was then left to cool and settle for half an hour; this was followed by centrifugal separation and successive washing with deionized water and anhydrous alcohol, which was repeated five times. Drying was performed at $80^{\circ} \mathrm{C}$ for $2 \mathrm{~h}$, in a vacuum drying oven, producing the nanometer-sized $\mathrm{ZnO}$ precursor. Finally, this precursor was calcined in a muffle at $600^{\circ} \mathrm{C}$ for $4 \mathrm{~h}$, which produced the nanometer-sized $\mathrm{ZnO}$ powder.

2.2. Characterization. The phase identity and crystalline size of the $\mathrm{ZnO}$ nanoparticles were determined using an $\mathrm{X}$ ray diffractometer (XRD). A scanning electron microscope (SEM) was used to make morphological observations on the $\mathrm{ZnO}$ and Er-doped $\mathrm{ZnO}$ nanoparticles. The optical properties of the samples were investigated by measuring the UVvis absorbance spectra and photoluminescence spectrum at room temperature. The photocatalytic activity of the $\mathrm{ZnO}$ powders was evaluated by measuring the degradation of methylene blue (MB) in water, in the UV region.

2.3. Photocatalytic Activity. The photocatalytic activity of the $\mathrm{ZnO}$ and Er-doped $\mathrm{ZnO}$ was determined by measuring the degradation of MB solution under UV illumination (32 W). The reaction was carried out with $0.05 \mathrm{~g}$ of photocatalyst suspended in a $100 \mathrm{~mL} \mathrm{MB}$ solution. The initial concentration of the MB solution was $10 \mathrm{mg} / \mathrm{L}$. Before the UV lamps were turned on to start the illumination, the solution was stirred for $0.5 \mathrm{~h}$ in the dark, to establish an adsorption/desorption equilibrium between the photocatalysts and the dye. The solution was sampled at $20 \mathrm{~min}$ intervals and centrifuged to remove any sediment, and then monitored using UV-vis spectroscopy.

\section{Results and Discussion}

3.1. Scanning Electron Microscopy (SEM)/Transmission Electron Microscopy (TEM). The SEM images in Figures 1(a) and $1(\mathrm{~b})$ show the size and distribution of the $\mathrm{ZnO}$ and Erdoped $\mathrm{ZnO}$ particles; the grain was smooth, the product showed no sintering reunion phenomena, and there was a narrow particle size distribution. The SEM investigations revealed that the crystallites were of nanometer size in all of the samples, but no significant change was observed in the particle size for the Er-doped particles. The average diameter was calculated as $\sim 45 \mathrm{~nm}$; the nanometer size of the particles led to an increased surface area and a consequent increase in the number of photocatalytic reaction sites, properties that improved the photocatalytic activity. Figures 1(c) and 1(e) compare the TEM images for the $\mathrm{ZnO}$ and the Er-doped $\mathrm{ZnO}$. The sizes were similar, which agreed well with the results from the diameter measurements. The selected area electron diffraction (SAED) patterns shown in Figures 1(d) and 1(f) for the $\mathrm{ZnO}$ and Er-doped $\mathrm{ZnO}$ revealed the polycrystalline nature of the materials, which could be well-indexed to diffractions from the (100), (002), and (101) planes of the hexagonal wurtzite structure. Furthermore, the difference in scattered spots between Figures 1(d) and 1(f) clearly showed the presence of secondary phase in addition to the wurtzite $\mathrm{ZnO}$.

3.2. X-Ray Diffraction Patterns (XRD). The XRD patterns for the Er-doped $\mathrm{ZnO}$ are shown in Figure 2, for different doping concentrations of Er. The sharp and intense peaks indicated that the samples were highly crystalline, and that the $\mathrm{ZnO}$ nanoparticles had a polycrystalline structure. The peaks were 


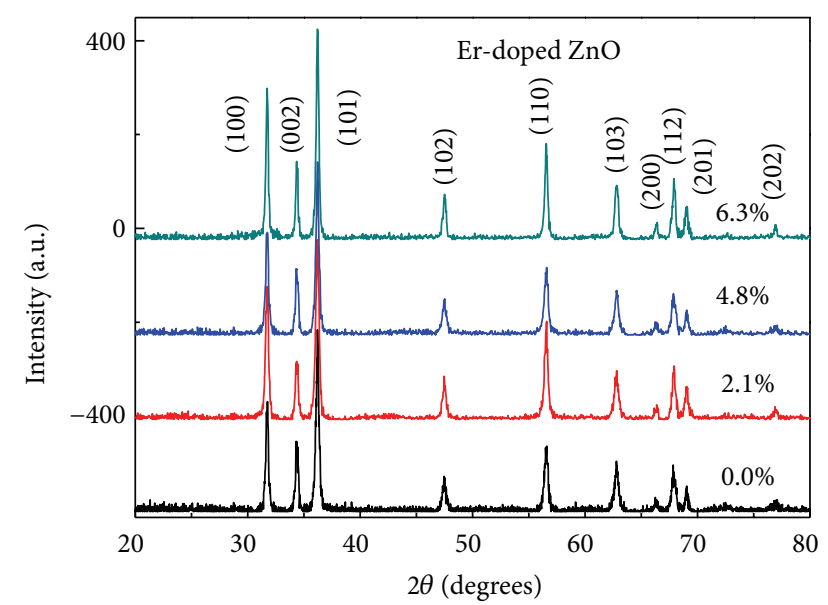

FIGURE 2: XRD patterns for $\mathrm{ZnO}$ and Er-doped $\mathrm{ZnO}$ with different doping concentrations.

at $31.8^{\circ}, 34.4^{\circ}, 36.3^{\circ}, 47.5^{\circ}, 56.6^{\circ}, 62.9^{\circ}, 66.4^{\circ}, 68.0^{\circ}, 69.1^{\circ}$, and $77.0^{\circ}$ and were indexed to the (100), (002), (101), (102), (110), (103), (200), (112), (201), and (202) planes of the ZnO crystal given by the standard data file (JCPDS file no. 36-1451). The XRD peaks for the (100), (002), and (101) planes indicated the formation of a pure-phase wurtzite $\mathrm{ZnO}$ structure. The XRD analysis further showed that the main diffraction peaks for the Er-doped $\mathrm{ZnO}$ composites were similar to those for the pure $\mathrm{ZnO}$ and corresponded to the hexagonal phase of $\mathrm{ZnO}$; this was in good agreement with the SAED results. According to the recent report [15], the shifted peaks in XRD studies revealed the occurrence of secondary phase in Er-dopped $\mathrm{ZnO}$ by solid-state reaction method with $\mathrm{Er}^{3+}$ content $>1 \%$. In this case, the peaks corresponding to the secondary phase in Figure 2 were not obvious. This is probably because of the doped $\mathrm{Er}^{3+}$ ions mainly substituted regular $\mathrm{Zn}^{2+}$ lattice sites (the ionic radius of $\mathrm{Er}^{3+}$ is smaller than the ionic radius of $\mathrm{Zn}^{2+}$ ) by homogeneous precipitation method.

3.3. Ultraviolet and Visible Absorption Spectra (UV-vis). UVvis spectra were measured for $\mathrm{ZnO}$ and $\mathrm{Er} / \mathrm{ZnO}$ in the wavelength region of $200-800 \mathrm{~nm}$, and the results are shown in Figure 3. The pure $\mathrm{ZnO}$ showed a maximum absorption peak at $363 \mathrm{~nm}$, and the absorption was mainly concentrated in the ultraviolet region, with less visible light absorption. The absorption band near $363 \mathrm{~nm}$ was due to the transition of electrons from the valence band to the conduction band. UVvis spectra of $\mathrm{Er} / \mathrm{ZnO}$ composite material showed a slightly redshifted peak at $375 \mathrm{~nm}$. This indicated an ineffective impurity band that was introduced by Er dopping [16].

It can be speculated that the metal ions were in the internal $\mathrm{ZnO}$ lattice and that the interaction of the doping ions with the $\mathrm{ZnO}$ destroyed part of the original lattice, forming lattice defects and making the $\mathrm{ZnO}$ absorption edge mobile, similar to results reported in the literature [17]. The redshift in the absorption wavelength range and the increase in the absorption intensity showed that the rate of formation of electron-hole pairs on the catalyst surface increased greatly, resulting in the catalyst exhibiting a higher

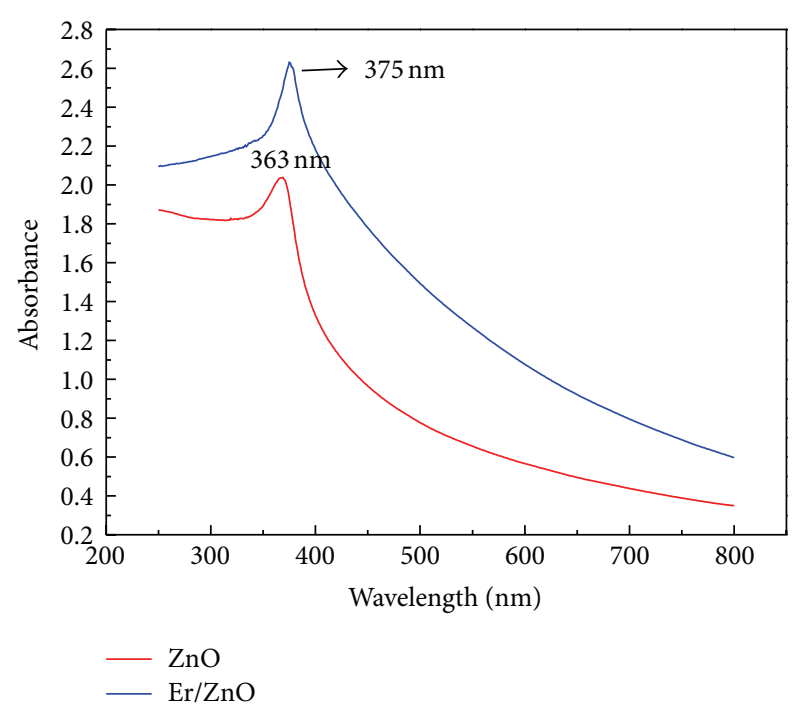

FIGURE 3: UV-vis spectra for $\mathrm{ZnO}$ and the Er-doped $\mathrm{ZnO}$ nanocomposites.

photocatalytic efficiency. The reason for the redshift in the absorption wavelength range for the Er-doped $\mathrm{ZnO}$ was likely the formation of defect energy levels between the valence and conduction bands in the $\mathrm{ZnO}$ band structure. This would have played an important role in improving the catalytic activity of the $\mathrm{ZnO}$.

3.4. Photoluminescence Spectra. Photocatalysts generate electrons and holes after being activated by light, and the recombination of some electrons and holes can release energy in the form of fluorescence emission.

Figure 4 shows room-temperature PL spectra for $\mathrm{ZnO}$ and the Er-ZnO nanocomposites containing different Er contents. All of the spectra showed two emission bands located at 396 and $484 \mathrm{~nm}$. While the sharper 396-nm emission band has typically been assigned to the near-band-edge emission in $\mathrm{ZnO}$ [18], the band in the visible spectral range (showing a peak at $484 \mathrm{~nm}$ ) has been attributed to the recombination of photogenerated holes with singly ionized charge states of the intrinsic defects such as oxygen vacancies, Zn interstitials, or impurities [19-22].

The characteristics of the PL spectra for the Er-doped $\mathrm{ZnO}$ nanocomposites were very similar to those of the spectra for the $\mathrm{ZnO}$ without Er. However, the intensity of the excitonic emission band increased compared with that for the $\mathrm{ZnO}$ without Er. This can be explained by the formation mechanism and structure of the Er-doped $\mathrm{ZnO}$ nanoparticles. $\mathrm{Er}^{3+}$ would have been removed from the conduction band of $\mathrm{ZnO}$ by the accumulated electrons and deposited on $\mathrm{ZnO}$ surface, and $\mathrm{Er}^{3+}$ requires three electrons for the reduction of each ion, and this would have resulted in more and more $\mathrm{ZnO}$ particles becoming attached together. This accumulation of $\mathrm{ZnO}$ particles in the presence of $\mathrm{Er}^{3+}$ would have caused an increased local concentration of excitons during photoexcitation, thus resulting in an increased excitonic emission intensity compared with the 


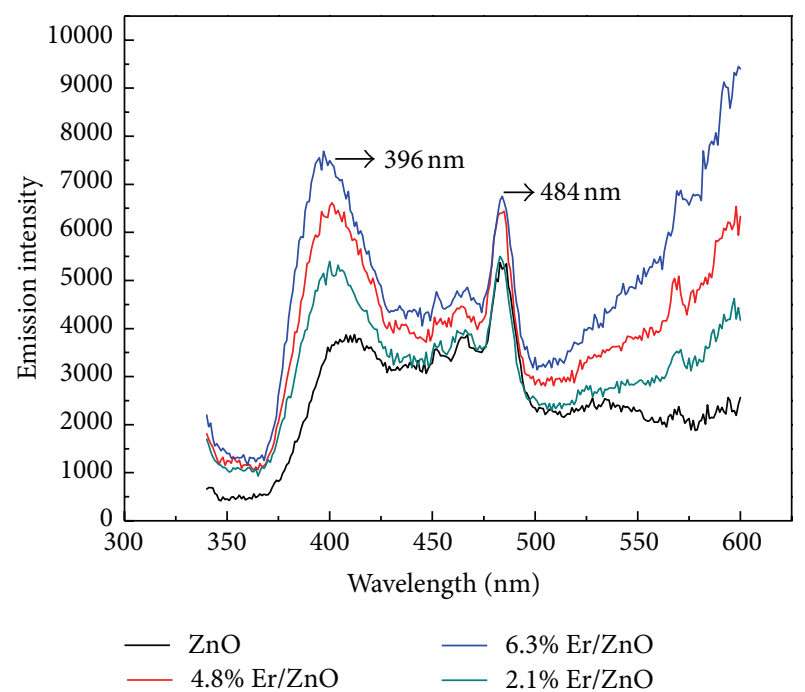

Figure 4: PL spectra of the Er-doped $\mathrm{ZnO}$ nanocomposites with different Er concentrations.

undoped $\mathrm{ZnO}$. The fluorescent light intensity was therefore enhanced with increasing Er contents.

The heavily doped product showed an extremely high PL intensity in the present case, which might have been related to the interaction between $\mathrm{ZnO}$ and Er. The majority of $\mathrm{Er}$ in the $\mathrm{ZnO}$ was likely associated with rare earth elements occupying substitutional $\mathrm{Zn}$ sites [23]. However, we did not observe $\mathrm{Er}^{3+}$ emission peaks. It is possible that weak $\mathrm{Er}^{3+}$ ion emission peaks were embedded in the signal from a strong, deep-level emission. The doping of metals and/or transition metals increases the number of surface defects and the surface area and surface defects play an important role in the photocatalytic activity of metal oxides.

3.5. Photocatalytic Activity. As Figure 5 shows, when the pure-phase, nanometer-sized $\mathrm{ZnO}$ was placed in a photocatalytic MB solution for $1 \mathrm{~h}$, the degradation rate was $69.28 \%$; with Er doping contents of $2.1 \%, 4.8 \%$, and $6.3 \%$, the photocatalysis degradation rates were $86.3 \%, 97.7 \%$, and $91.3 \%$, respectively. However, the photocatalytic degradation rate of the composite photocatalyst with a doping concentration of $6.3 \%$ was lower than that of the photocatalyst with a doping concentration of $4.8 \%$.

Similar to metal doping, the use of rare earth ions provides electron traps that suppress electron-hole recombination. The holes are then able to migrate towards the surface of the catalyst and oxidize the adsorbed organic compounds $[24,25]$. The Er-doping of the nanometer-sized $\mathrm{ZnO}$ catalyst resulted in increased fluorescence emission, and increases in the electron-hole pair concentration. The Er ions provided a favorable redox potential, which resulted in the photoproduction of electronic defects and the inhibition of electron-hole recombination. The surface favored the generation of positive holes, which were considered to be the active center of the reaction; hence, the excellent generation of holes led in turn to the effective removal of the MB dye.

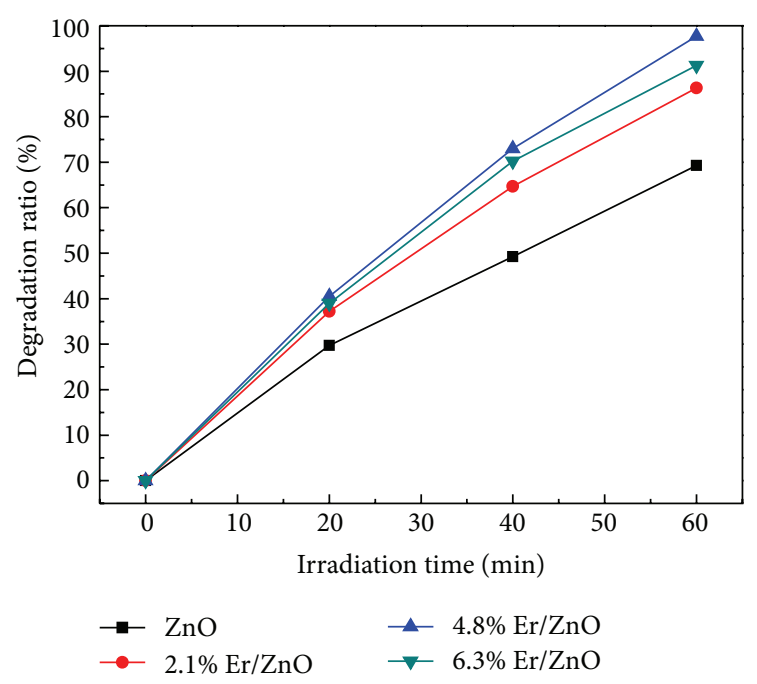

(a)

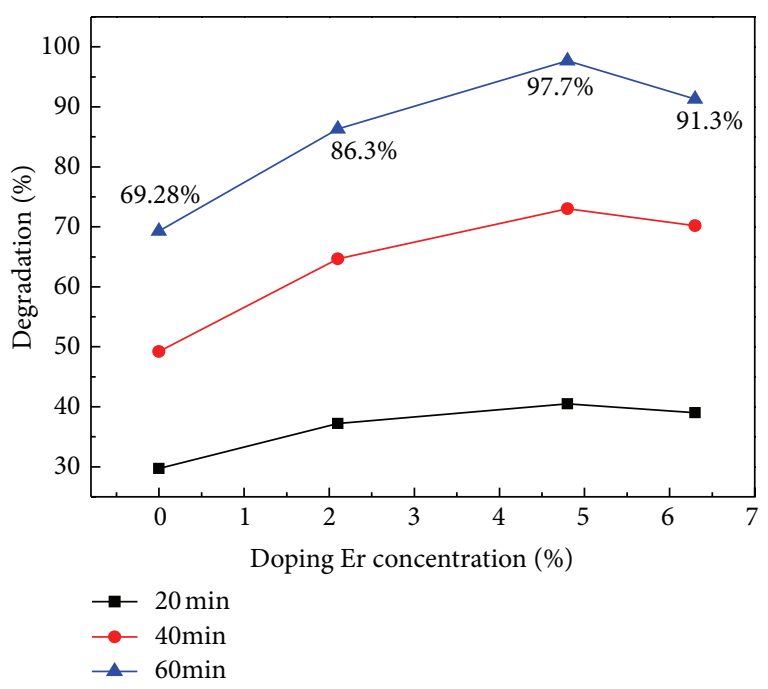

(b)

Figure 5: (a) Photocatalytic degradation curve for $\mathrm{ZnO}$ and Erdoped $\mathrm{ZnO}$ under UV-light irradiation; (b) degradation rates of Erdoped $\mathrm{ZnO}$ with different $\mathrm{Er}$ concentrations.

However, the photocatalytic experiments showed that the photocatalytic effects did not increase monotonically as the doping amount was increased; the effects began to decrease when the Er content was increased to $6.3 \%$. This phenomenon was mainly due to the fact that when the rare earth ion concentration was increased to a certain level, the light penetrated into the $\mathrm{ZnO}$ past the space-charge layer, and the effective separation of the light-generated electronhole pairs was suppressed. Accordingly, there is an optimal concentration of dopant ions; at this concentration, the thickness of the space-charge layer and the depth of the light penetration were similar. Further, too high a quantity of rare earth ions on the surface of the $\mathrm{ZnO}$ also increased the recombination of electron-hole pairs, thereby reducing the photocatalytic activity. 


\section{Conclusion}

$\mathrm{ZnO}$ and Er-doped $\mathrm{ZnO}$ photocatalysts with different molar ratios of Er/Zn were prepared via the homogeneous precipitation method and consisted of wurtzite-type $\mathrm{ZnO}$. The doping of Er into the $\mathrm{ZnO}$ expanded the range of absorption and enhanced the intensity of the fluorescence emission with increasing the surface area and surface defects, which played an important role in promoting the photocatalytic activity of the $\mathrm{ZnO}$. The results of the experiments showed that doping Er into $\mathrm{ZnO}$ modified the optical properties of the $\mathrm{ZnO}$ and greatly improved the photocatalytic activity of the $\mathrm{ZnO}$. This study of Er modified $\mathrm{ZnO}$ provides theoretical and methodological support for improving the photocatalytic activity of photocatalyst in the future.

\section{References}

[1] M. Nirmala and A. Anukaliani, "Synthesis and characterization of undoped and TM (Co, Mn) doped $\mathrm{ZnO}$ nanoparticles," Materials Letters, vol. 65, no. 17-18, pp. 2645-2648, 2011.

[2] S. Anandan, A. Vinu, K. L. P. Sheeja Lovely et al., "Photocatalytic activity of La-doped $\mathrm{ZnO}$ for the degradation of monocrotophos in aqueous suspension," Journal of Molecular Catalysis A, vol. 266, no. 1-2, pp. 149-157, 2007.

[3] P. V. Kamat, "Photochemistry on nonreactive and reactive (semiconductor) surfaces," Chemical Reviews, vol. 93, no. 1, pp. 267-300, 1993.

[4] E. Pelizzetti and N. Serpone, Homogeneous and Heterogeneous Photo-Catalysis, Reidel, Dordrecht, The Netherlands, 1986.

[5] E. R. Carraway, A. J. Huffman, and M. R. Hoffmann, "Photocatalytic oxidation of organic acids on quantum-sized semiconductor colloids," Environmental Science and Technology, vol. 28, no. 5, pp. 786-793, 2004.

[6] M. G. Nair, M. Nirmala, K. Rekha, and A. Anukaliani, "Structural, optical, photo catalytic and antibacterial activity of $\mathrm{ZnO}$ and Co doped $\mathrm{ZnO}$ nanoparticles," Materials Letters, vol. 65, no. 12, pp. 1797-1800, 2011.

[7] H. Li, Z. Zhang, J. Huang, R. Liu, and Q. Wang, "Optical and structural analysis of rare earth and $\mathrm{Li}$ co-doped $\mathrm{ZnO}$ nanoparticles," Journal of Alloys and Compounds, vol. 550, pp. 526-530, 2013.

[8] Y. Liu, W. Luo, R. Li, G. Liu, M. R. Antonio, and X. Chen, "Optical spectroscopy of $\mathrm{Eu}^{3+}$ doped $\mathrm{ZnO}$ nanocrystals," Journal of Physical Chemistry C, vol. 112, no. 3, pp. 686-694, 2008.

[9] J. C. Ronfard-Haret, "Electric and luminescent properties of $\mathrm{ZnO}$-based ceramics containing small amounts of $\mathrm{Er}$ and $\mathrm{Mn}$ oxide," Journal of Luminescence, vol. 104, no. 1-2, pp. 1-12, 2003.

[10] A. K. Pradhan, K. Zhang, G. B. Loutts, U. N. Roy, Y. Cui, and A. Burger, "Structural and spectroscopic characteristics of $\mathrm{ZnO}$ and ZnO:Er ${ }^{3+}$ nanostructures," Journal of Physics Condensed Matter, vol. 16, no. 39, pp. 7123-7130, 2004.

[11] J. Ebothe, W. Gruhn, A. Elhichou, I. V. Kityk, R. Dounia, and M. Addou, "Giant piezooptics effect in the $\mathrm{ZnO}-\mathrm{Er}^{3+}$ crystalline films deposited on the glasses," Optics and Laser Technology, vol. 36, no. 3, pp. 173-180, 2004.

[12] W. C. Yang, C. W. Wang, J. C. Wang et al., "Aligned Er-doped $\mathrm{ZnO}$ nanorod arrays with enhanced $1.54 \mu \mathrm{m}$ infrared emission," Journal of Nanoscience and Nanotechnology, vol. 8, no. 7, pp. 3363-3368, 2008.
[13] V. Kumari, V. Kumar, B. P. Malik, R. M. Mehra, and D. Mohan, "Nonlinear optical properties of erbium doped zinc oxide (EZO) thin films," Optics Communications, vol. 285, no. 8, pp. 2182-2188, 2012.

[14] J. C. Sin, S. M. Lam, K. T. Lee, and A. R. Mohamed, "Fabrication of erbium-doped spherical-like $\mathrm{ZnO}$ hierarchical nanostructures with enhanced visible light-driven photocatalytic activity," Materials Letters, vol. 91, pp. 1-4, 2013.

[15] J. Rita and R. Rajaram, "Synthesis and characterization of rare earth ion doped Nano ZnO," Nano-Micro Letters, vol. 4, no. 2, pp. 65-72, 2012.

[16] C. F. Zhe, Handbook of Zinc Oxide and Related Materials, CRC Press, Taylor \& Francis, Boca Raton, Fla, USA, 2013.

[17] Y. Ling, W. Jiang, X. Wu, and X. Bai, "Preparation and visible light photocatalytic properties of $(\mathrm{Er}, \mathrm{La}, \mathrm{N})$-Codoped $\mathrm{TiO}_{2}$ nanotube array films," Journal of Nanoscience and Nanotechnology, vol. 9, no. 2, pp. 714-717, 2009.

[18] S. Y. Bae, C. W. Na, J. H. Kang, and J. Park, "Comparative structure and optical properties of Ga-, In-, and Sn-doped $\mathrm{ZnO}$ nanowires synthesized via thermal evaporation," Journal of Physical Chemistry B, vol. 109, no. 7, pp. 2526-2531, 2005.

[19] U. Ozgour, Y. I. Alivov, C. Liu et al., "A comprehensive review of $\mathrm{ZnO}$ materials and devices," Journal of Applied Physics, vol. 98, no. 4, Article ID 041301, 103 pages, 2005.

[20] D. C. Look, "Recent advance in $\mathrm{ZnO}$ materials and devices," Materials Science and Engineering B, vol. 80, pp. 383-387, 2001.

[21] T. Parvin, N. Keerthiraj, I. A. Ibrahim, S. Phanichphant, and K. Byrappa, "Photocatalytic degradation of municipal wastewater and brilliant blue dye using hydrothermally synthesized surface-modified silver-doped $\mathrm{ZnO}$ designer particles," International Journal of Photoenergy, vol. 2012, Article ID 670610, 8 pages, 2012.

[22] D. Zhang and F. Zeng, "Visible light-activated cadmiumdoped $\mathrm{ZnO}$ nanostructured photocatalyst for the treatment of methylene blue dye," Journal of Materials Science, vol. 47, no. 5, pp. 2155-2161, 2012.

[23] U. Wahl, E. Rita, J. G. Correia, E. Alves, and J. P. Araújo, "Implantation site of rare earths in single-crystalline $\mathrm{ZnO}$," Applied Physics Letters, vol. 82, no. 8, pp. 1173-1175, 2003.

[24] P. K. Dutta, S. O. Pehkonen, V. K. Sharma, and A. K. Ray, "Photocatalytic oxidation of arsenic (III): evidence of hydroxyl radicals," Environmental Science and Technology, vol. 39, no. 6, pp. 1827-1834, 2005.

[25] L. Zhang and Y. Zhu, "A review of controllable synthesis and enhancement of performances of bismuth tungstate visiblelight-driven photocatalysts," Catalysis Science and Technology, vol. 2, no. 4, pp. 694-706, 2012. 

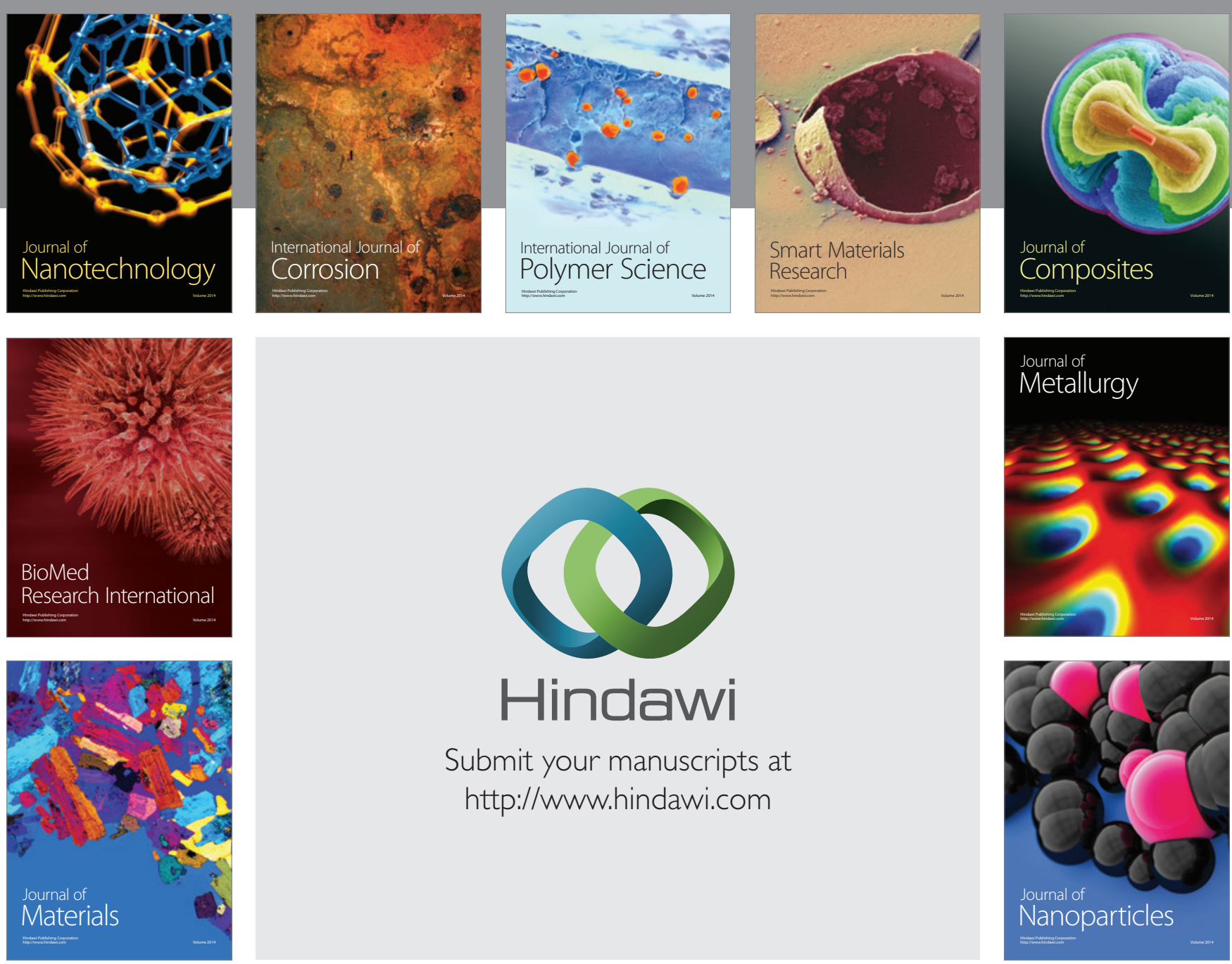

Submit your manuscripts at http://www.hindawi.com
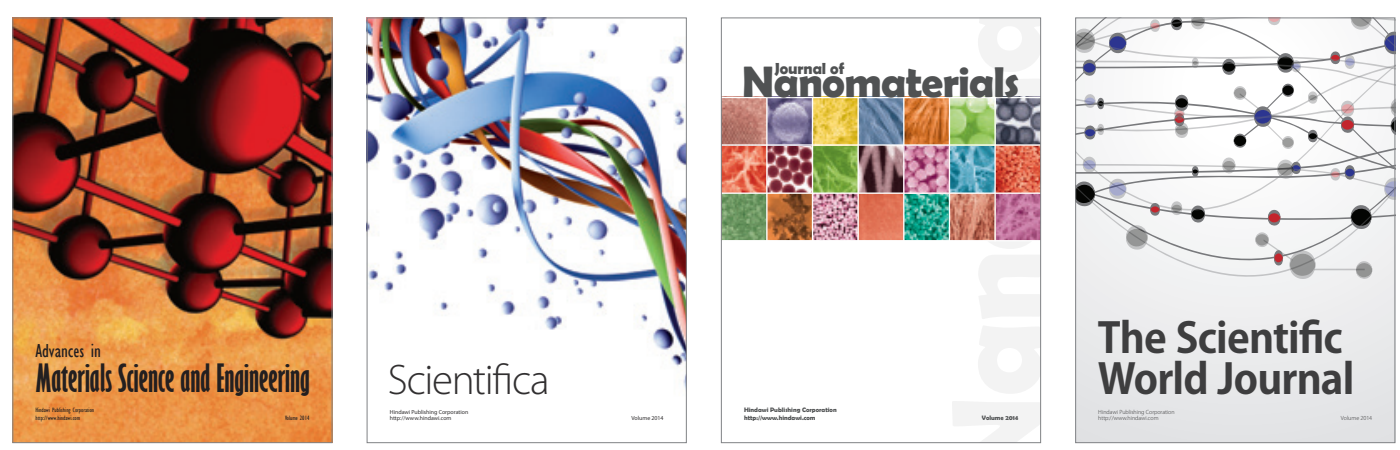

\section{The Scientific World Journal}
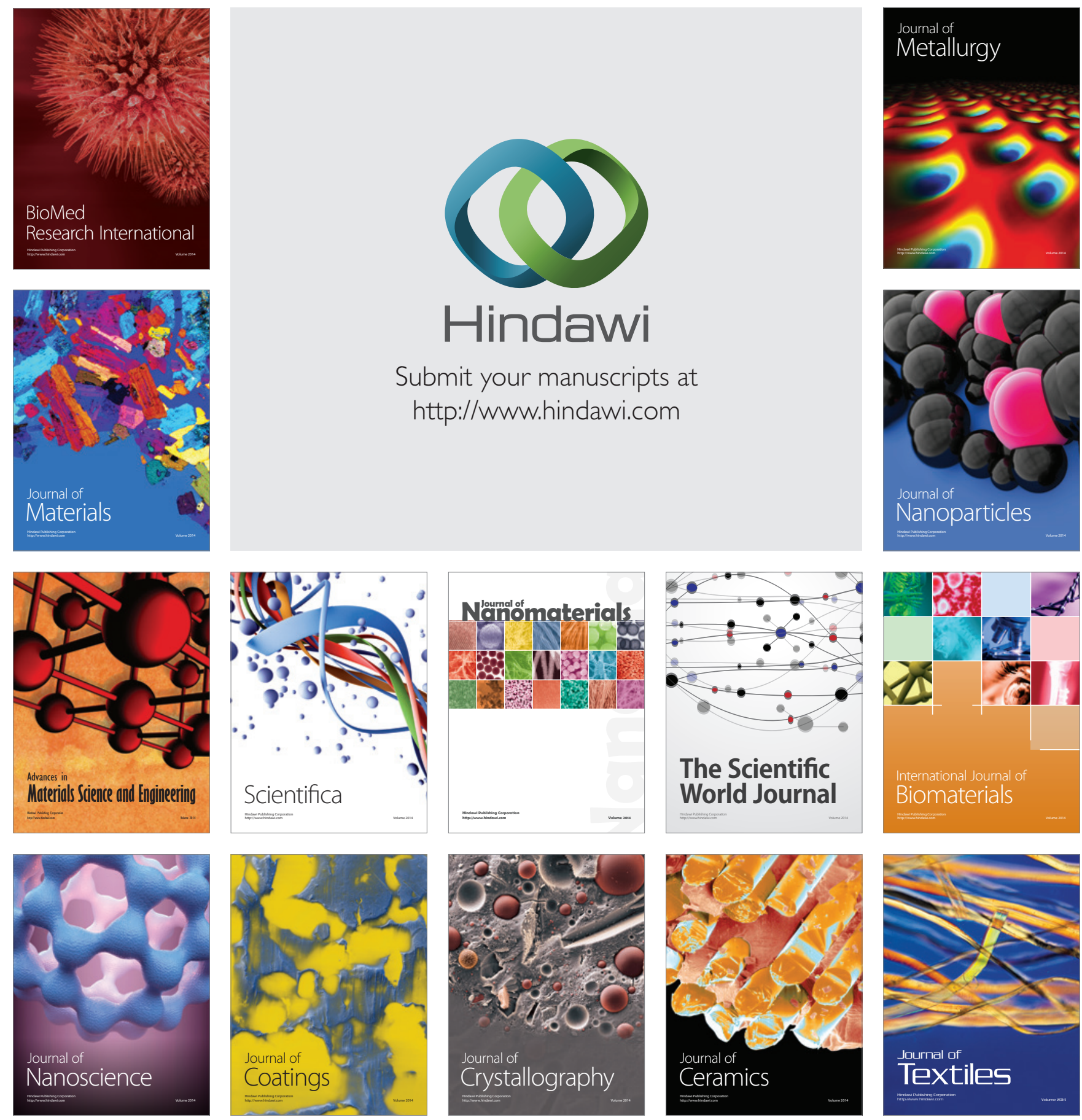